\title{
Inhibition of Proteasomal Deubiquitinase by Silver Complex Induces Apoptosis in Non-Small Cell Lung Cancer Cells
}

\author{
Xin Chen ${ }^{a}$ Qianqian Yang ${ }^{a}$ Jinghong Chen ${ }^{a, b} \quad$ Peiquan Zhang ${ }^{a} \quad$ Qingtian Huang $^{a}$ \\ Xiaolan Zhang ${ }^{\mathrm{a}}$ Li Yang $^{\mathrm{a}}$ Dacai Xu ${ }^{\mathrm{a}}$ Chong Zhao ${ }^{\mathrm{a}, \mathrm{c}}$ Xuejun Wang ${ }^{\mathrm{a}, \mathrm{d}}$ \\ Jinbao Liu ${ }^{\mathrm{a}}$ \\ aProtein Modification and Degradation Lab, State Key Lab of Respiratory Disease, School of \\ Basic Medical Sciences, Affiliated Tumor Hospital of Guangzhou Medical University, Guangzhou, \\ ${ }^{b}$ Department of Hematology, The Second Affiliated Hospital, Guangzhou Medical University, \\ Guangzhou, 'Department of Gastroenterology, Guangzhou Digestive Disease Center, Guangzhou First \\ People's Hospital, Guangzhou Medical University, Guangzhou, China, dDivision of Basic Biomedical \\ Sciences, Sanford School of Medicine of the University of South Dakota, Vermillion, USA
}

\section{Key Words}

Proteasome $\cdot$ Deubiquitinases $\cdot$ Silver complex $・$ Apoptosis $\bullet$ Lung cancer

\begin{abstract}
Background/Aims: The ubiquitin proteasome system (UPS) is responsible for the degradation of most intracellular proteins, and proteasomal deubiquitinases (DUBs) have recently been highlighted as novel anticancer targets. It is well documented that copper complexes can inhibit UPS function through targeting both $20 \mathrm{~S}$ proteasome and proteasomal DUBs. The antineoplastic activities of silver complexes have received much attention, but the exact mechanisms are not fully elucidated. In this study, we aim to investigate the effects of a novel silver complex $\left[\mathrm{Ag}\left(\mathrm{S}_{2} \mathrm{CN}\left(\mathrm{C}_{2} \mathrm{H}_{5}\right)_{2}\right)\right]_{6}$ (AgDT) on UPS function and its anticancer potential in nonsmall cell lung cancer (NSCLC). Methods: Cell viability assay (i.e., the MTS assay) and flow cytometry assay were used to analyze the cell viability and apoptosis. Proteasome inhibition was measured using $20 \mathrm{~S}$ proteasome activity assay and $19 \mathrm{~S}$ proteasomal DUBs activity assay. Western blot analysis and immunohistochemistry were performed to detect protein levels. The in vivo antitumor activity of AgDT was assessed with nude xenografts. Results: Silver ions, alone or in combination with disulfiram (DSF), induced UPS inhibition in NSCLC cells mainly through inhibition of proteasomal DUBs activities. Silver complex AgDT triggered intracellular accumulation of ubiquitinated proteins, and prevented the degradation of surrogate substrate GFPu. Mechanistically, AgDT potently inhibited the activities of proteasomal DUBs USP14 and UCHL5, without altering the 20S proteasome peptidases. Moreover, AgDT induced apoptosis in NSCLC cells and significantly inhibited tumor growth in xenografts. Conclusion: Our

X. Chen and Q. Yang contributed equally to this work.

\begin{tabular}{ll}
\hline Jinbao Liu & Protein Modification and Degradation Lab, State Key Lab of Respiratory Disease, \\
& School of Basic Medical Sciences, Affiliated Tumor Hospital of Guangzhou Medical University, \\
& Guangzhou (China); E-Mail jliu@gzhmu.edu.cn
\end{tabular}
\end{abstract}




\section{Cellular Physiology Cell Physiol Biochem 2018;49:780-797 \\ \begin{tabular}{ll|l} 
DOI: 10.1159/000493041 & $\begin{array}{l}\text { O } 2018 \text { The Author(s). Published by S. Karger AG, Basel } \\
\text { www.karger.com/cpb }\end{array}$
\end{tabular} \\ Chen et al.: Inhibition of Proteasomal DUBs by Silver Complex}

findings suggest that silver complex AgDT is a novel metal-based proteasomal DUBs inhibitor, and pharmacologic inhibition of USP14 and UCHL5 could prove to be an effective therapeutic strategy for NSCLC.

(C) 2018 The Author(s)

Published by S. Karger AG, Basel

\section{Introduction}

The ubiquitin proteasome system (UPS) is the major protein degradation pathway in eukaryotes and thereby plays a central role in regulating fundamental cellular processes such as the cell cycle and apoptosis [1,2]. The $26 \mathrm{~S}$ proteasome, a large ATP-dependent multisubunit proteolytic molecular machine, can dissociate into two subcomplexes: the $20 \mathrm{~S}$ core particle and the 19S regulatory particle. In the catalytic chamber of $20 \mathrm{~S}$ proteasomes there are three distinct catalytic subunits, known as $\beta 1, \beta 2$ and $\beta 5$, which exhibit caspase-like (C-like), trypsin-like (T-like) and chymotrypsin-like (CT-like) activities, respectively [1]. Due to the remarkable efficacy of the $20 \mathrm{~S}$ proteasome inhibitor bortezomib for the treatment of multiple myeloma (MM), it is anticipated that targeting the upstream of proteasomal degradation can be a potential anticancer therapeutic strategy $[3,4]$. A good example is the proteasomal deubiquitinases (DUBs) inhibitor, which shows efficacy in MM disease models and overcomes bortezomib resistance [5]. In humans, there are three DUBs associated with the 19S proteasome: POH1/Rpn11, USP14/Ubp6, and UCHL5/Uch37. POH1 is a zinc-dependent metalloprotease which belongs to the JAMM family, while USP14 and UCHL5 are members of the cysteine protease USP and UCH families. Although the precise roles of proteasomal DUBs are not completely understood, they regulate the degradation of ubiquitinated proteins by removing the ubiquitinated chains from the substrates. It was previously reported that higher USP14 expression was detected in the non-small cell lung cancer (NSCLC) tumor tissues, compared with the matched normal control, and over-expression of USP14 was associated with shorter overall survival in NSCLC patients [6]. Additionally, knockdown of UCHL5 induces apoptosis, while overexpression of UCHL5 promotes cell growth in NSCLC cells [7]. Thus, inhibition of USP14 and UCHL5 may represent potentially a new strategy for NSCLC treatment.

Several copper-binding agents have been investigated for their ability to bind copper and impair UPS function in malignant cells [8-10]. We have previously demonstrated that copper pyrithione (CuPT), a copper complex used as antifouling paint biocides, induces cancer cell death by targeting both $19 \mathrm{~S}$ proteasomal DUBs and 20S proteasome peptidases [10]. Although copper complexes exhibit strong anticancer activities, the undesired side effects may prevent them from entering clinical trials [11]. This prompted us to search for new metal-based anticancer agents with decreased toxic side effects and improved specificity in inhibition of UPS function. Silver complexes have proven to exhibit low toxicity towards humans [12]. The use of silver and its salts as antimicrobial medicine can go back to centuries ago $[13,14]$. It is only in recent years that silver complexes have also been studied for their antitumor activities, which are closely related to their interaction with nucleic acids and thiol (sulfhydryl) groups of proteins [15]. However, the underlying molecular mechanisms of the potential anticancer effects of silver complexes are largely unclear.

Disulfiram (DSF) has been clinically used for the treatment of alcoholism and has an excellent safety profile [16]. A growing body of evidence suggests that DSF possesses potential anti-tumor activities both in vitro and in vivo [17-19]. The addition of DSF to a combination regimen of cisplatin and vinorelbine appeared to prolong survival in patients with newly diagnosed NSCLC in clinical trials [20]. In this work, we have demonstrated that $\mathrm{Ag}$ ions alone or the combination of Ag ions and DSF induces the accumulation of ubiquitinated proteins mainly through inhibition of proteasomal DUBs. The silver complex AgDT, which is synthesized from silver and diethyldithiocarbamate (the active metabolite of DSF), can efficiently induce apoptosis in NSCLC cells through targeting proteasomal DUBs USP14 and UCHL5. We also investigated the antineoplastic effects of AgDT in the NSCLC cell xenograft mouse models. 


\section{Cellular Physiology Cell Physiol Biochem 2018;49:780-797

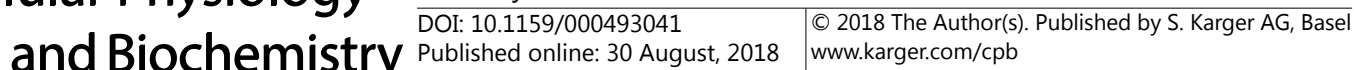 Chen et al.: Inhibition of Proteasomal DUBs by Silver Complex}

\section{Materials and Methods}

\section{Materials}

The agents used in this study were purchased from following sources: silver nitrate, copper nitrate, calcium nitrate, disulfiram (DSF), tetrathiomolybdate (TM), ethylenediaminetetraacetic acid (EDTA), desferrioxamine (DFO), N-acetyl-L-cysteine (NAC), catalase (CAT), N-ethylmaleimide (NEM) (SigmaAldrich, St. Louis, MO); bortezomib (Cell Signaling Technology, Beverly, MA, USA); b-AP15, Z-LLE-AMC, Boc-LRR-AMC, Suc-LLVY-AMC, purified human 20S proteasome, purified human 26S proteasome, HAubiquitin-vinyl sulfone (HA-Ub-VS), and Ub-AMC (BostonBiochem, Cambridge, MA, USA). Antibodies were purchased from following sources: anti-caspase 3/8/9, anti-cleaved caspase 3/8/9, anti-PARP, anti-K48linked polyubiquitin (D9D5), and anti-USP14 (D8Q6S) (Cell Signaling Technology, Beverly, MA, USA); antiubiquitin (P4D1) and anti-GFP (B-2) (Santa Cruz Biotechnology, Santa Cruz, CA); anti-GAPDH and anti-HAtag (Bioworld Technology, Nanjing, China); anti-UCHL5 (Abcam, Cambridge, UK).

\section{Cell viability assay}

MTS assay (CellTiter 96Aqueous One Solution reagent; Promega, Shanghai, China) was used to test cell viability as we previously reported [21]. Briefly, $1 \times 10^{5} / \mathrm{ml}$ cells in $100 \mu$ l were treated with either vehicle or AgDT for 48 hours. 3 hours before culture termination, $20 \mu \mathrm{l}$ MTS was added to the wells. The absorbance density was read on a 96 -well plate reader at wavelength $490 \mathrm{~nm}$. IC ${ }_{50}$ values were calculated.

\section{Cell death assay}

Apoptosis was determined by flow cytometry using Annexin V-fluoroisothiocyanate (FITC) and propidium iodide (PI) double staining. Cells were incubated with AgDT, then collected and washed with the binding buffer (Sigma-Aldrich) and then incubated in the working solution (100 $\mu$ l binding buffer with 0.3 $\mu \mathrm{l}$ Annexin V-FITC) for $15 \mathrm{~min}$ in dark; the cells were then washed and resuspended with the binding buffer. PI was added immediately before flow cytometric analysis. In addition, to monitor temporal changes in the incidence of cell death in the live culture condition, Annexin V/PI or PI staining was also performed in situ as we described previously [22].

\section{Western blot analysis}

Whole cell lysates were prepared in RIPA buffer ( $1 \times \mathrm{PBS}, 1 \% \mathrm{NP}-40,0.5 \%$ sodium deoxycholate, $0.1 \%$ SDS) supplemented with $10 \mathrm{mM} \beta$-glycerophosphate, $1 \mathrm{mM}$ sodium orthovanadate, $10 \mathrm{mM} \mathrm{NaF}, 1 \mathrm{mM}$ phenylmethylsulfonyl fluoride (PMSF), and 1× Roche Complete Mini Protease Inhibitor Cocktail (Roche, Indianapolis, IN). Western blotting was performed as we previously described [21]. In brief, equal amounts of total protein extract from cultured cells were fractionated by $12 \%$ SDS-PAGE and electrically transferred onto PVDF membranes. Primary antibodies and appropriate horseradish peroxidase-conjugated secondary antibodies were used to detect the designated proteins. The bound secondary antibodies on the PVDF membrane were reacted to the ECL detection reagents (Santa Cruz, CA) and exposed to X-ray films (Kodak, Japan).

\section{0 proteasome peptidase activity assays}

These assays were performed as we previously reported [23], in which fluorogenic substrates Z-LLEAMC, Boc-LRR-AMC and Suc-LLVYAMC were used for caspase-like, trypsin-like, and chymotrypsin-like activities, respectively. To evaluate in vivo proteasome inhibition, lung cancer cells were treated with AgDT or bortezomib for 3 hours. The cells were lysed in ice-cold lysis buffer. Equal amounts of protein from each sample were then incubated at $37^{\circ} \mathrm{C}$ with $50 \mu \mathrm{M}$ fluorogenic substrates. To assay for direct inhibition of the $20 \mathrm{~S}$ proteasome in vitro, purified human $20 \mathrm{~S}$ proteasomes were incubated with the agents to be tested for 30 minutes at $37^{\circ} \mathrm{C}$ before the addition of the fluorogenic substrates. Fluorescence intensity was measured using a microplate reader at excitation of $350 \mathrm{~nm}$ and emission of $438 \mathrm{~nm}$ (Varioskan Flash 3001, Thermo, USA). 


\section{\begin{tabular}{ll} 
Cellular Physiology & Cell Physiol Biochem 2018;49:780-797 \\
\hline Dol: 10.1159/000493041 & 2018 The Author(s). Published by S. Karger AG, Basel
\end{tabular}

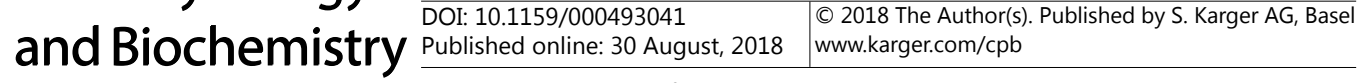 \\ Chen et al.: Inhibition of Proteasomal DUBs by Silver Complex}

Deubiquitinase activity assay

This was performed as we previously reported [23]. Briefly, cell lysates $(5 \mu \mathrm{g})$ or $26 \mathrm{~S}$ proteasomes (25 $\mathrm{nM}$ ) were dissolved in DUB buffer containing $50 \mathrm{mM}$ Tris- $\mathrm{HCl}(\mathrm{pH} 7.5), 20 \mathrm{mM} \mathrm{NaCl}, 5 \mathrm{mM} \mathrm{MgCl}{ }_{2}$ and $200 \mu \mathrm{M}$ ATP, and pretreated with AgDT or NEM for 30 minutes at $37^{\circ} \mathrm{C}$, then incubated with the substrate Ub-AMC. Free AMC generated from substrate cleavage was temporally recorded with a microplate reader (Varioskan Flash 3001, Thermo, USA).

\section{HA-UbVS labeling assays}

This was performed as we described previously [23]. Purified $26 \mathrm{~S}$ proteasomes ( $25 \mathrm{nM}$ ) pretreated with AgDT for 30 minutes or cell lysates $(5 \mu \mathrm{g})$ from AgDT treated cancer cells were incubated with HAUbVS for 1 hour at $37^{\circ} \mathrm{C}$, followed by boiling in the reducing sample buffer and fractionated with SDS-PAGE. After transferring to PVDF membranes, HA-UbVS labeled DUBs were immunodetected using an HA antibody.

Blood samples and isolation of peripheral blood monocytes (PBMC)

Peripheral blood samples of normal controls and acute myeloid leukemia (AML) patients were obtained from Department of Hematology, The Second Affiliated Hospital of Guangzhou Medical University. The use of these materials is approved by the Ethics Committee of these two Institutions with the permission of the patients and volunteers. Totally six patients with AML and six volunteers were recruited in this preclinical study. PBMC were isolated by Ficoll-Paque (Pharmacia, Uppsala, Sweden) density gradient and washed two times in phosphate-buffered saline (PBS). The culture of PBMC was performed as described earlier [21].

\section{Measurement of ROS generation}

A549 and H1299 cells were treated with AgDT in the absence or presence of antioxidants for 1 hour. The cells were harvested and incubated with the free serum medium with addition of $10 \mu \mathrm{M}$ of DCFH-DA (Sigma-Aldrich, St. Louis, MO) for 20 minutes at $37^{\circ} \mathrm{C}$ in the dark. In the presence of ROS, DCFH penetrates the cells and is in turn oxidized to DCF. DCF fluorescence was analyzed using fluorescence microscopy.

\section{Tumor xenograft model}

All animal protocols used were approved by the Institutional Animal Care and Use Committee of Guangzhou Medical University. The nude Balb/c mice were obtained from Guangdong Laboratory Animal Monitoring Institute and were housed in barrier facilities with a 12 hours light-dark cycle, with food and water available ad libitum. $1 \times 10^{7}$ of A549 or H1299 cells was inoculated subcutaneously on the flanks of 5 -week-old male nude mice. At 72 hours after inoculation, the mice were treated with either vehicle $(10 \%$ DMSO, 30\% Cremophor and 60\% normal saline) or AgDT (2.5 mg/kg/day, intraperitoneal injection) for totally 2 weeks, respectively. Tumor volumes were recorded and calculated as previously reported [21].

\section{Immunohistochemistry}

Formalin-fixed xenografts were embedded in paraffin and sectioned according to standard techniques as we previously reported [21]. Tumor xenograft sections $(4 \mu \mathrm{m})$ were immunostained using the MaxVision kit (Maixin Biol) according to the manufacturer's instructions. The primary antibodies were used as indicated. $50 \mu \mathrm{l}$ MaxVisionTM reagent was applied to each slide. Color was developed with $0.05 \%$ diaminobenzidine and $0.03 \% \mathrm{H}_{2} \mathrm{O}_{2}$ in $50 \mathrm{mM}$ Tris- $\mathrm{HCl}$ (pH 7.6), and the slides were counterstained with hematoxylin. A negative control for every antibody was also included for each xenograft specimen by substituting the primary antibody with preimmune rabbit serum.

\section{Statistical analysis}

All the results were expressed as Mean \pm SD, where applicable. GraphPad Prism 7 software (GraphPad Software) was used for statistical analysis. Student's $t$ test was used to compare the differences between two groups. $P$ value of $<0.05$ was considered to be statistically significant. 


\section{Cellular Physiology Cell Physiol Biochem 2018;49:780-797 \begin{tabular}{ll|l} 
and Biochemistry Published online: 30 August, 2018 & $\begin{array}{l}\text { (c) 2018 The Author(s). Published by S. Karger AG, Basel } \\
\text { www.karger.com/cpb }\end{array}$
\end{tabular}

\section{Results}

\section{Ag ions inhibit the proteasome function}

Silver ions have proven to possess anticancer activity in vitro $[24,25]$. In this study, we found that $20 \mu \mathrm{M} \mathrm{Ag}$ ions (silver nitrate), but not $\mathrm{Cu}$ ions (copper nitrate) or Ca ions (calcium nitrate) induced marked accumulation of total and K48-linked ubiquitinated proteins in A549 cells (Fig. 1A). The accumulation of (K48-linked) ubiquitinated proteins may result from either inhibition of $20 \mathrm{~S}$ proteasome-mediated proteins degradation or inability to remove polyubiquitin chain by DUBs on the $26 \mathrm{~S}$ proteasome. Thus, we next investigate the effects of $\mathrm{Ag}$ ions on $20 \mathrm{~S}$ proteasome activity and proteasomal DUB activity in vitro. $\mathrm{Cu}$ ions have previously been reported to inhibit UPS function by targeting the 20 proteasome peptidases [8]. We observed that $\mathrm{Ag}$ ions, similarly to $\mathrm{Cu}$ ions, inhibited all the three peptidases activities of the $20 \mathrm{~S}$ proteasome, with $\mathrm{IC}_{50}$ in the range of 3-5 $\mu \mathrm{M}$ (Fig. $1 \mathrm{~B}, \mathrm{C})$. The $20 \mathrm{~S}$ proteasome inhibitor bortezomib inhibited the C-like and CT-like activities without affecting T-like activity (Fig. 1B), which was consistent with previous reports [26]. Interestingly, in comparison to $\mathrm{Cu}$ ions, $\mathrm{Ag}$ ions exhibited much stronger inhibitory effect on proteasomal DUB activity (Fig. 1D, E). N-ethylmaleimide (NEM), a general inhibitor of cysteine DUBs, completely inhibited the activity of proteasomal DUBs (Fig. 1D, E). However, Ca ions, even at $20 \mu \mathrm{M}$, had no effects on either $20 \mathrm{~S}$ proteasome activity or proteasomal DUB activity (Fig. 1C, E). Collectively, these results show that Ag ions can potently inhibit the proteasome function.

Fig. 1. Ag ions inhibit proteasomes. A, Ag ions induce accumulation of ubiquitinated proteins in cancer cells. A549 cells were treated with the indicated concentrations $(\mu \mathrm{M})$ of $\mathrm{Ag}$ ions (silver nitrate), $\mathrm{Cu}$ ions (copper nitrate) or $\mathrm{Ca}$ ions (calcium nitrate) for 6 hours, and then total (Ub) and K48-linked (K48-) ubiquitinated proteins were analyzed with western blot. Bortezomib (BZ, $0.1 \mu \mathrm{M}$ ) was used as a positive control. GAPDH was used as a loading control. B and C, Effects of different metal ions on 20S proteasome activities. Purified 20S proteasomes were treated with the indicated doses of $\mathrm{Ag}$ ions (B), $\mathrm{Cu}$ or $\mathrm{Ca}$ ions (C), and then the $\mathrm{C}$-like, $\mathrm{T}$-like and CT-like activities of the

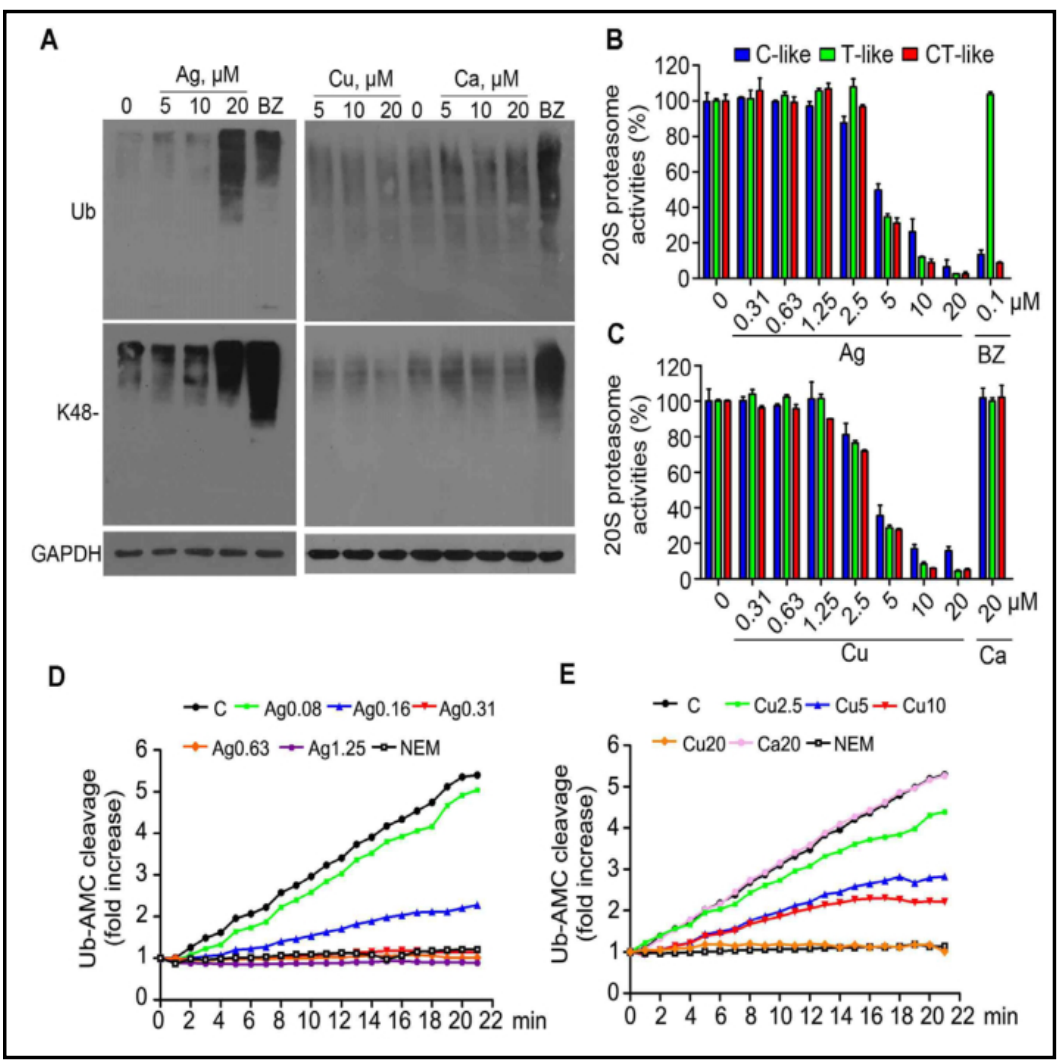
20S proteasome were measured using specific fluorogenic substrates. Bortezomib (BZ, $0.1 \mu \mathrm{M}$ ) was used as a positive control. Mean \pm SD $(n=3)$. D and E, Effects of different metal ions on 26S proteasomal DUB activities. Purified 26S proteasomes were treated with the indicated doses $(\mu \mathrm{M})$ of $\mathrm{Ag}$ ions (D), $\mathrm{Cu}$ or Ca ions (E), and then the DUB activities at different times was recorded using the Ub-AMC substrate. NEM (2 mM) was used as a positive control. The experiment was repeated three times and all yielded similar results. DUB activity was expressed as fold relative fluorescence units difference over time. $\mathrm{C}$, control. 


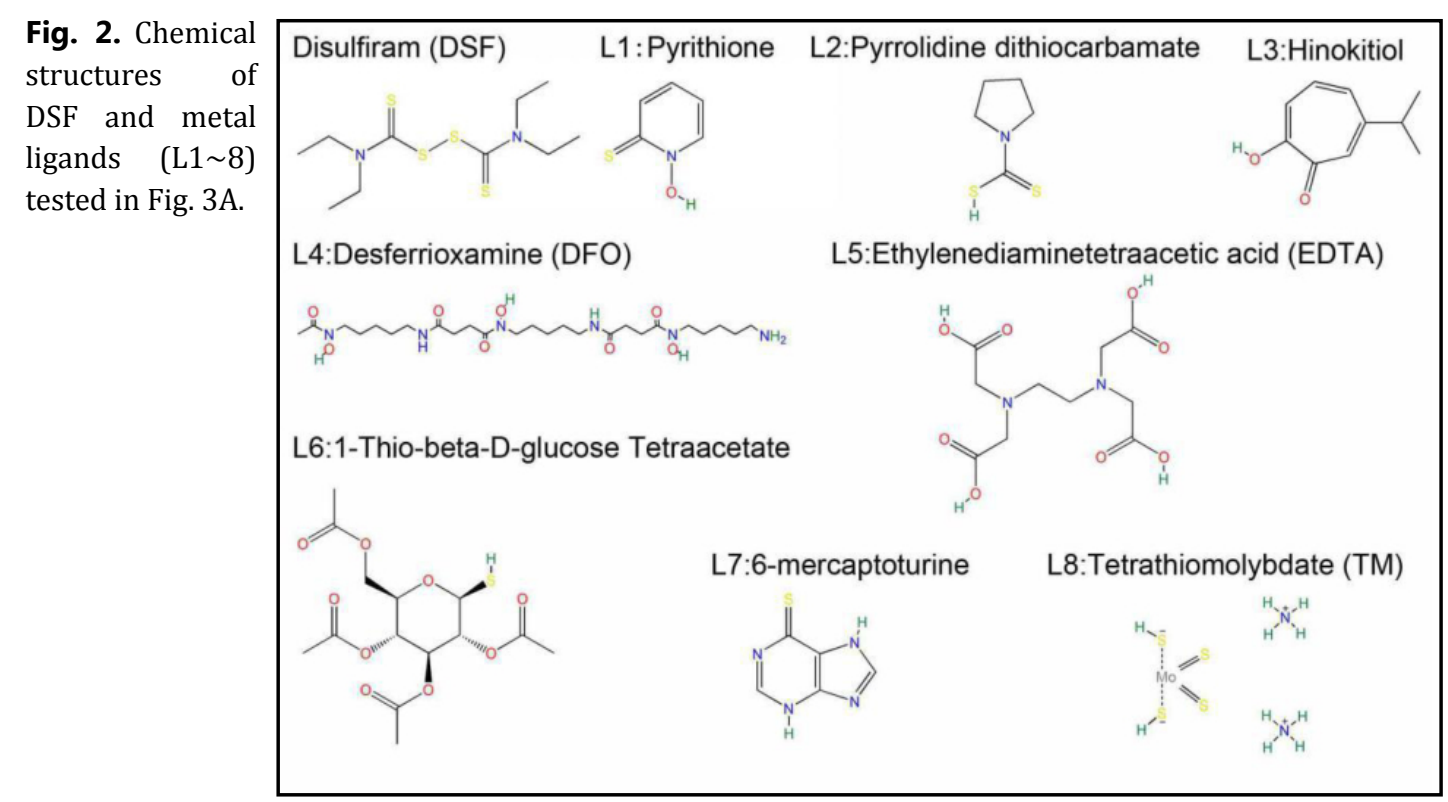

Combination of Ag ions and disulfiram (Ag/DSF) synergistically enhanced cytotoxicity and proteasome inhibition

We next tested the cytotoxic effects of Ag ions in combination with a range of metal ligands (the chemical structures were shown in Fig. 2) in lung cancer cells. We found that Ag ions alone at $20 \mu \mathrm{M}$ decreased cell viability of A549 cells by $\sim 80 \%$, but no cytotoxicity was seen at doses less than $10 \mu \mathrm{M}$ (Fig. 3A). Compared to other eight metal ligands, DSF exhibited the strongest synergistic effects with equimolar amounts of Ag ions, dramatically inhibited cell viability in A549 cells with the $\mathrm{IC}_{50}$ of $1.04 \mu \mathrm{M}$ when combined with $\mathrm{Ag}$ ions. Furthermore, we observed that $\mathrm{Ag} / \mathrm{DSF}$ induced accumulation of ubiquitinated proteins and apoptosis more effectively than Ag ions or DSF alone (Fig. 3B, C). However, Ag ions and TM (ligand L8) combination treatment did not induce proteasome inhibition in A549 cells (Fig. 3B). Moreover, TM but not EDTA (ligand L5) reversed Ag ions- or Ag/DSF-induced cell death and proteasome inhibition (Fig. 3D, E).

We next investigated the effects of $\mathrm{Ag} / \mathrm{DSF}$ on $20 \mathrm{~S}$ proteasome activity and $26 \mathrm{~S}$ proteasomal DUB activity in vitro. We observed that Ag/DSF did not inhibit 20S proteasome activity even at $2.5 \mu \mathrm{M}$ (Fig. 3F), but it dramatically decreased proteasomal DUB activity at nanomolar concentration (Fig. 3G). Interestingly, we found that DSF moderately inhibited the proteasomal DUB activity (Fig. 3H). However, DSF even at $20 \mu \mathrm{M}$ did not inhibit $20 \mathrm{~S}$ proteasome activity (Fig. 3F), which was consistent with previous reports [8]. Collectively, these experiments show that Ag ions combined with DSF exert cytotoxicity in NSCLC cells by proteasome inhibition.

\section{AgDT triggers accumulation of ubiquitinated proteins}

It is known that diethyldithiocarbamate (DDTC) is an active metabolite of DSF [16], so we synthesized the silver (I) DDTC complex $\left[\mathrm{Ag}\left(\mathrm{S}_{2} \mathrm{CN}\left(\mathrm{C}_{2} \mathrm{H}_{5}\right)_{2}\right)\right]_{6}$ (abbreviated as AgDT in this study) as described in the literature [27]. The X-ray crystal structure and refinement data of AgDT was shown in Fig. 4A and Table 1. To test whether AgDT blocks cellular proteasome function, we used clonal HEK293 cells stably expressing a degron CL1-fused green fluorescence protein (GFPu), which is a surrogate substrate of the UPS [28, 29]. We found that, similarly to bortezomib, AgDT accumulated GFPu and ubiquitinated proteins in GFPu-HEK293 cells (Fig. 4B, C), indicating that silver complex AgDT can inhibit proteasome function. 
Fig. 3. The c o m bi n a tion of $\mathrm{Ag}$ ions and DSF results in enhanced antitumor efficacy. $\mathrm{A}, \mathrm{Ag}$ ions and DSF synergistically decrease cancer cell viability. A549 cells were exposed to $\mathrm{Ag}$ ions, $\mathrm{Ag}$ ions plus different metal ligands (1:1) (top) or ligand alone (bottom) at the indicated doses for $48 \mathrm{~h}$, and then cell viability was detected with the MTS assay. Mean \pm SD $(n=3)$. $\mathrm{B}, \mathrm{Ag} / \mathrm{DSF}$ induces accumulation of u b i quitina ted proteins. A549 cells were treated with the indicated doses $(\mu \mathrm{M})$ of $\mathrm{Ag}$ ions, DSF, $\mathrm{Ag} / \mathrm{DSF}$, $\mathrm{TM}$, or $\mathrm{Ag} / \mathrm{TM}$ for 6 hours, and then total (Ub) and K48-linked (K48-
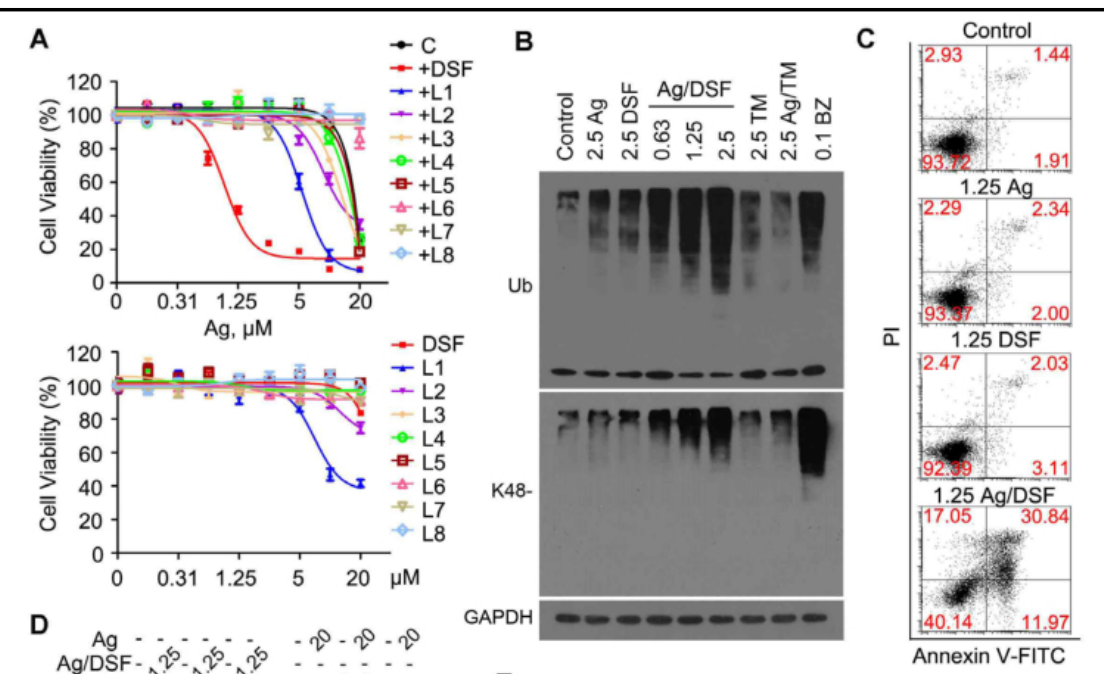

E
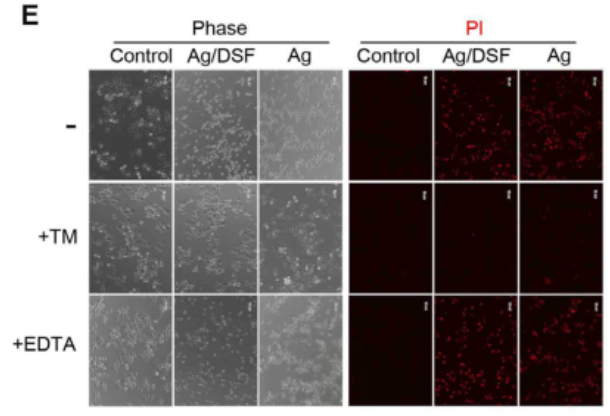

G

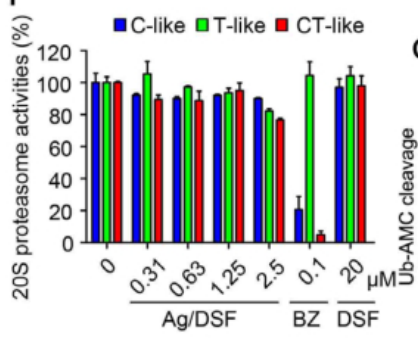

$\mathbf{G} \rightarrow \mathrm{C} \rightarrow 0.04 \rightarrow 0.08 \rightarrow 0.16 \mathrm{H} \rightarrow \mathrm{C} \rightarrow 0.63 \rightarrow 1.25$

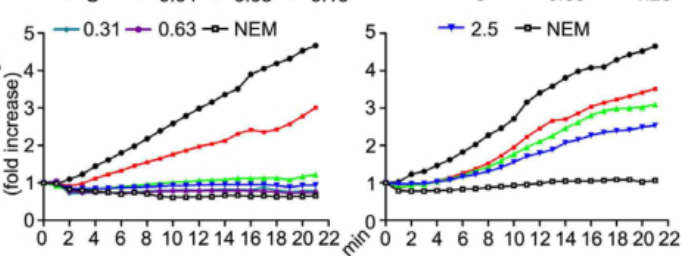

) ubiquitinated

proteins were analyzed with western blot. Bortezomib (BZ $0.1 \mu \mathrm{M})$ was used as a positive control. C, Ag ions plus DSF induce apoptosis. A549 cells were exposed to Ag ions, DSF or Ag/DSF at the indicated doses $(\mu \mathrm{M})$ for 24 hours, and then cell apoptosis was detected using Annexin V/propidium (PI) staining followed by flow cytometry. D and E, Effects of TM and EDTA on Ag/DSF- or Ag ions-induced cell death and proteasome inhibition. D, A549 cells were incubated with $1.25 \mu \mathrm{M} \mathrm{Ag} / \mathrm{DSF}$ or $20 \mu \mathrm{M}$ Ag ions in the absence or presence of $20 \mu \mathrm{M}$ TM or EDTA for 6 hours. The cell lysates were then subject to western blot analyses for the indicated proteins. GAPDH was used as a loading control. E, A549 cells were treated as described in (D) for 6 hours, and then cells were stained with PI and imaged under a fluorescent microscope. Scale bar $=50 \mu \mathrm{m}$. F, Effects of Ag/DSF on 20S proteasome activities. Purified 20S proteasomes were treated with the indicated doses of Ag/DSF, $0.1 \mu \mathrm{M}$ bortezomib (BZ) or $20 \mu \mathrm{M}$ DSF, and then the activities of the $20 \mathrm{~S}$ proteasome peptidases were measured using specific fluorogenic substrates. Mean $\pm \mathrm{SD}(\mathrm{n}=3) .{ }^{*} \mathrm{P}<0.05$, versus control. $\mathrm{G}$ and $\mathrm{H}$, Effects of Ag/DSF on 26S proteasomal DUB activities. Purified 26S proteasomes were treated with the indicated doses $(\mu \mathrm{M})$ of Ag/DSF $(G)$ or DSF $(H)$, and then the DUB activities at different times was recorded by using the Ub-AMC substrate. NEM $(2 \mathrm{mM})$ was used as a positive control. The experiment was repeated three times and all yielded similar results. DUB activity was expressed as fold relative fluorescence units difference over time. $\mathrm{C}$, control. 


\section{Cellular Physiology and Biochemistry \begin{tabular}{l|l} 
DOI: 10.1159/000493041 & $\begin{array}{l}\text { O } 2018 \text { The Author(s). Published by S. Karger AG, Basel } \\
\text { wwwwkarger.com/cpb }\end{array}$
\end{tabular}

Fig. 4. AgDT $\mathrm{i} n \mathrm{~h}$ i b i t $s$ p rote a s o m e function in cancer cells. A, The crystal structure of AgDT. B, AgDT a c c u m u lates $\mathrm{GFPu}$ protein, a surrogate UPS substrate. GFPuHEK293 cells were treated with the indicated doses $(\mu \mathrm{M})$ of AgDT or $0.1 \mu \mathrm{M}$ bortezomib (BZ) for 6 hours, and then ubiquitinated proteins (Ub) and $\mathrm{GFPu}$ proteins were detected with western blot. C, AgDT accumulates GFPu. G F P u - HE K 293 cells were treated with AgDT 0.63 $\mu \mathrm{M})$ or bortezomib (BZ, $0.1 \mu \mathrm{M}$ ) for 6 hours, the GFPu fluorescent images are shown. Scale bar $=50 \mu \mathrm{m}$. D, AgDT induces cytotoxicity in

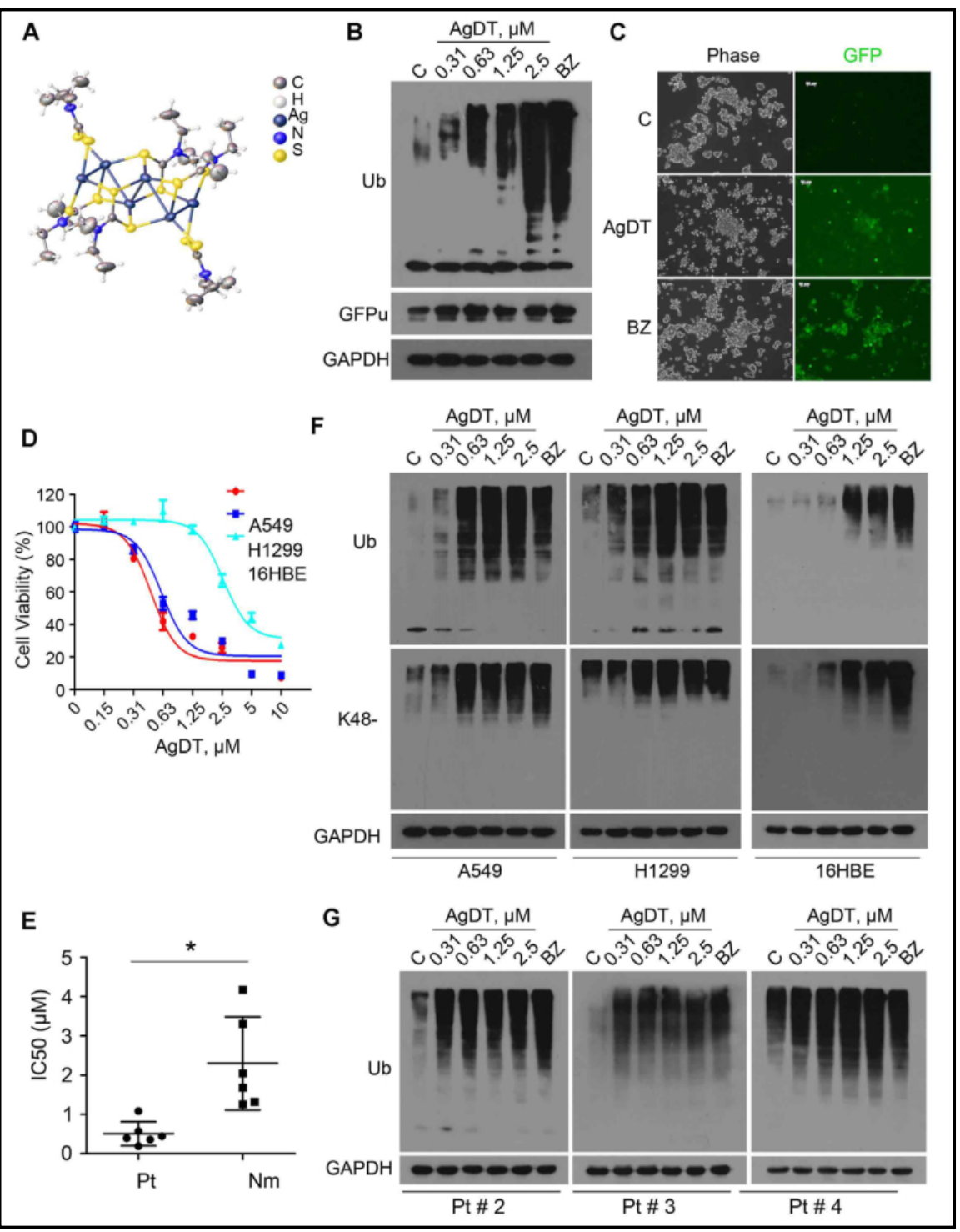
cancer cell lines.

A549, H1299 and 16HBE cells were exposed to AdDT in various concentrations for 48 hours, and then cell viability was detected by MTS assay. Mean \pm SD $(n=3)$. E, The antineoplastic effects of AgDT on PBMC obtained from six AML patients. PBMC from six AML patients (Pt) or normal controls (Nm) were treated with increasing doses of AgDT for 24 hours, and the cell viability was determined by MTS assay. The scatter plot of the $\mathrm{IC}_{50}$ values in each group is shown. Mean $\pm \mathrm{SD}(\mathrm{n}=6) .{ }^{*} \mathrm{P}<0.05$. F, AgDT induces accumulation of ubiquitinated proteins. A549, H1299 and 16HBE cells were treated with various concentrations of AgDT or $0.1 \mu \mathrm{M}$ bortezomib (BZ) for 6 hours, and then total (Ub) and K48-linked (K48-) ubiquitinated proteins were analyzed with western blot. G, PBMC from patients (Pt) were treated with the indicated doses of AgDT or $0.1 \mu \mathrm{M}$ bortezomib (BZ) for 6 hours, and then ubiquitinated proteins (Ub) were detected with western blot. GAPDH was used as a loading control. C, control.

We next investigated the anticancer effects of AgDT. As shown in Fig. 4D, 16HBE bronchial epithelial cells or A549 and H1299 lung cancer cells were treated with various concentrations of AgDT for $48 \mathrm{~h}$, and cell viability was measured with the MTS assay. AgDT decreased the cell viability of A549 and H1299 cells in a dose-dependent manner, with the $\mathrm{IC}_{50}$ values of 0.49 and $0.60 \mu \mathrm{M}$, respectively. Importantly, we observed that 16HBE cells were less sensitive to $\mathrm{AgDT}$ than lung cancer cells, the $\mathrm{IC}_{50}$ value was $2.59 \mu \mathrm{M}$. In addition, we 


\section{Cellular Physiology Cell Physiol Biochem 2018;49:780-797 \begin{tabular}{l|l|l} 
and Biochemistry & Published online: 30 August, 2018 & $\begin{array}{l}\text { (c) 2018 The Author(s). Published by S. Karger AG, Basel } \\
\text { www.karger.com/cpb }\end{array}$
\end{tabular}

found that AgDT inhibited cell viability of cancer cells from AML patients with average $\mathrm{IC}_{50}$ value of $0.51 \mu \mathrm{M}$ while in normal controls its average $\mathrm{IC}_{50}$ value was $2.30 \mu \mathrm{M}$ (Fig. 4E). These results demonstrate that AgDT selectively induces cytotoxicity in cancer cells. Accordingly, we observed that AgDT induced marked accumulation of total and K48-linked ubiquitinated proteins in A549 and H1299 lung cancer cells in a dose-dependent manner, similarly to bortezomib; however, AgDT showed relatively weak effect on the levels of ubiquitinated proteins in 16HBE cells (Fig. 4F). Moreover, treatment with AgDT obviously increased the level of ubiquitinated proteins in the cancer cells from AML patients (Fig. 4G). These results further support the conclusion that AgDT can induce proteasome inhibition in cancer cells.

AgDT inhibits $19 S$ proteasomal DUBs but not 20 s proteasome activities

To determine the target of AgDT, we first detected the effect of AgDT on 20S proteasome peptidase activities both in vitro and in live cells. We found that AgDT, even at a dose as high as $2.5 \mu \mathrm{M}$, did not inhibit any of the three peptidase activities of purified $20 \mathrm{~S}$ proteasomes, which was distinct from bortezomib (Fig. 5A). Consistently, these activities were not significantly affected in AgDT-treated A549 and H1299 cells, either (Fig. 5B). These experimental findings indicate that AgDT does not inhibit the 20S proteasome.

Then we tested the effects of AgDT on proteasomal DUBs activities. First, the activities of DUBs from either purified 26S proteasomes or cell lysates were detected. As shown in Fig. 5C, AgDT markedly inhibited the DUBs activities of purified proteasomes in a dose-dependent manner. However, AgDT yielded only very weak effects on the total DUB activities in cell lysates, which is expected because cell lysates contain many non-proteasomal DUBs (Fig. 5D). In contrast, NEM completely inhibited both proteasomal and cytosolic DUBs activities (Fig. $5 C, D)$. These results demonstrate that AgDT is an inhibitor of proteasomal DUBs, rather than a general DUB inhibitor. Next, we performed a competition binding assay between AgDT and HA-UbVS. We found that similarly to USP14 and UCHL5 inhibitor b-AP15, AgDT (1.25 and $2.5 \mu \mathrm{M}$ ) could block the binding of HA-UbVS to cysteine DUBs USP14 and UCHL5 in purified $26 \mathrm{~S}$ proteasomes (Fig. 5E). We also performed competition assays between AgDT and HAUbVS in live cells. We observed AgDT (1.25 and $2.5 \mu \mathrm{M})$ resulted in an obvious increase in the unlabeled form of USP14 and UCHL5, but minimal inhibition on the labeling of total cytosolic DUBs with HA-UbVS (Fig. 5F). Taken together, these results consistently support that AgDT is an inhibitor of proteasomal DUBs (USP14 and UCHL5).

\section{AgDT induces apoptosis in NSCLC cells}

We next analyzed the ability of AgDT to induce cell death in cancer cells. Exposure of A549 and H1299 cells to escalating concentrations of AgDT resulted in significant increases in the proportion of AnnexinV/PI-positive cells as detected by fluorescent microscopy (Fig. 6A) or flow cytometry (Fig. 6B), supporting that AgDT induces apoptosis in cancer cells. In addition, treatment of A549 and H1299 cells with AgDT induced PARP cleavage and 


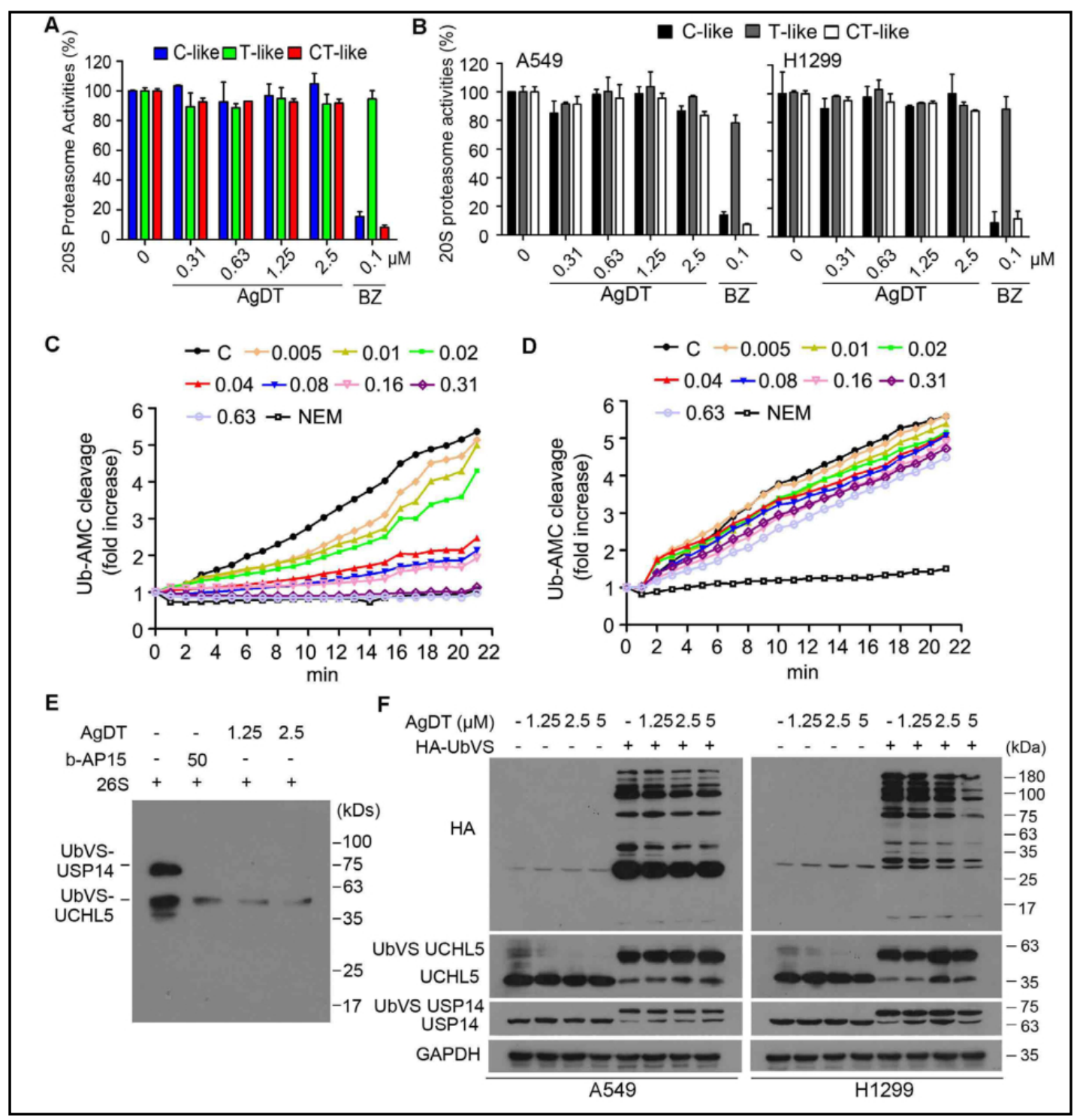

Fig. 5. AgDT inhibits 26S proteasomal DUB activities. A, Effects of AgDT on 20S proteasome activities. Purified 20S proteasomes were treated with the indicated doses of AgDT or $0.1 \mu \mathrm{M}$ bortezomib (BZ), and then the activities of the 20S proteasome peptidases were measured using specific fluorogenic substrates, respectively. B, Effects of AgDT on the 20S proteasome activities in live cells. A549 and H1299 cells were incubated with indicated doses of AgDT or $0.1 \mu \mathrm{M}$ bortezomib (BZ) for 3 hours, the cells were lysed in icecold lysis buffer, and then the activities of the $20 \mathrm{~S}$ proteasome peptidases were measured using specific fluorogenic substrates, respectively. Mean \pm SD $(n=3)$. C, Effects of AgDT on 26S proteasomal DUB activities. Purified 26S proteasomes were treated with the indicated doses of AgDT or $2 \mathrm{mM} \mathrm{NEM}$, and then the DUB activities at different times was recorded by using the Ub-AMC substrate. The experiment was repeated three times and all yielded similar results. DUB activity was expressed as fold relative fluorescence units difference over time. D, Effects of AgDT on Ub-AMC cleavage by DUBs in cell lysate. A549 cell lysate was treated as (C), and then DUB activity kinetics was monitored. C, control. E, Active-site-directed labeling of proteasomal DUBs. Purified 26S proteasomes were treated with AgDT (1.25 and $2.5 \mu \mathrm{M})$ or b-AP15 (50 $\mu \mathrm{M}$ ), then labeled with HA-UbVS, and the resultant products were subject to western blot analysis for HA. F, A549 and H1299 were treated with the indicated doses of AgDT for 3 hours. Whole-cell lysates were labeled with HA-UbVS, followed with sodium dodecyl sulfate polyacrylamide gel electrophoresis (SDS-PAGE) and immunoblotting with the indicated antibodies. GAPDH was used as a loading control. 


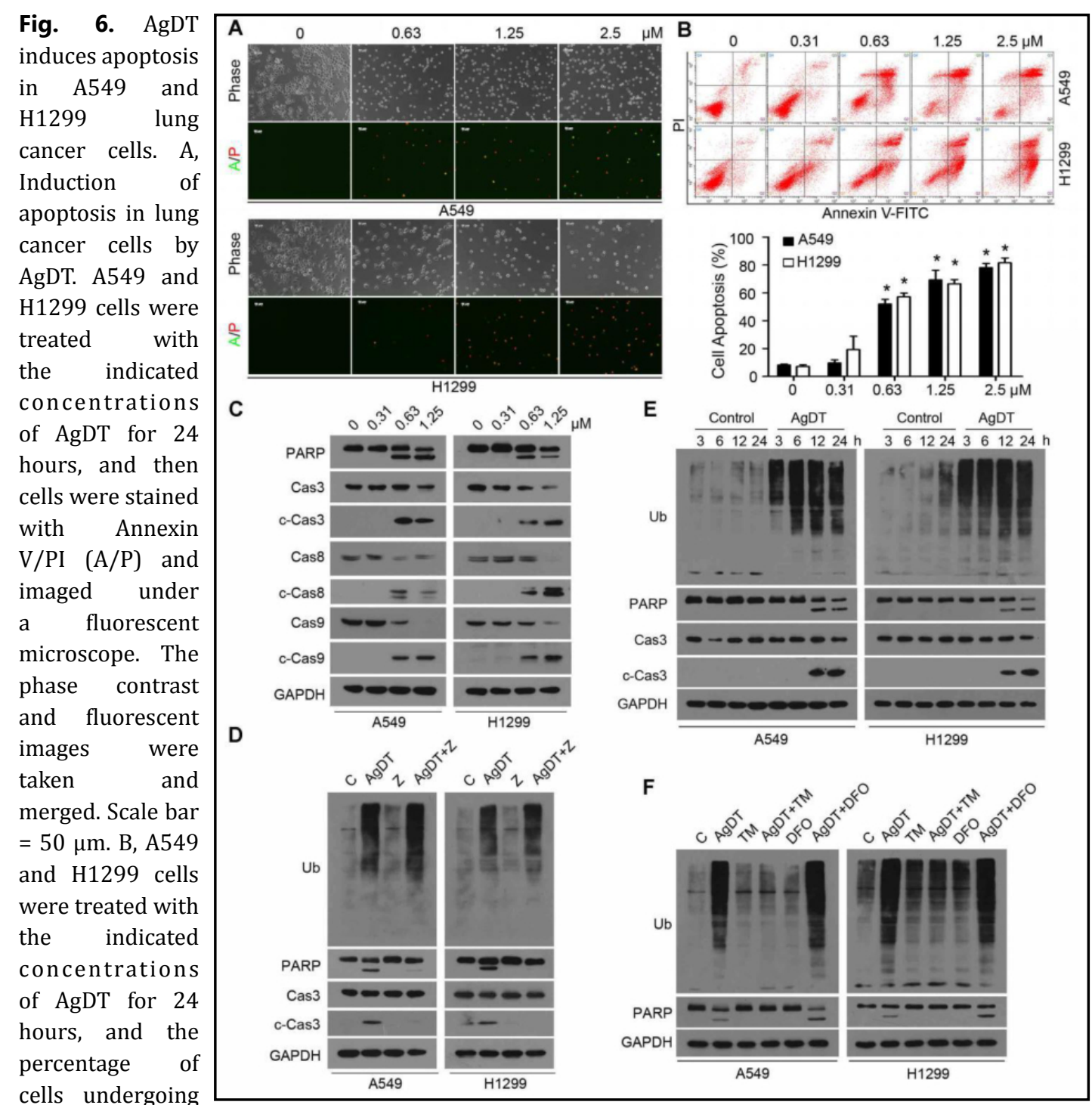

a p o p t o s i s

was determined with Annexin V/PI staining followed by flow cytometry. The extent of cell apoptosis was summarized in the associated bar graph. Mean \pm SD $(n=3) .{ }^{*} \mathrm{P}<0.05$ versus control. $\mathrm{C}$, AgDT induces cleavage of PARP and caspases-3, -8 and -9 in lung cancer cells. A549 and H1299 cells were treated with various concentrations of AgDT for 24 hours; PARP and caspase-3, -8 and - 9 cleavage were analyzed with western blot. D, Effect of z-VAD-fmk on AgDT-induced proteasome inhibition and apoptosis. A549 cells were incubated with $0.63 \mu \mathrm{M}$ AgDT with or without $100 \mu \mathrm{M} \mathrm{z}$-VAD-fmk (Z) for 24 hours, and then ubiquitinated proteins (Ub), PARP and caspase-3 cleavage proteins were measured with western blot analyses. C, control. E, AgDT-induced accumulation of ubiquitinated proteins occurs before apoptosis becomes evident. A549 and H1299 cells were treated with $0.63 \mu \mathrm{M}$ AgDT for indicated periods of time. The cell lysates were analyzed by western blot using the indicated antibodies. F, A549 and H1299 cells were treated with AgDT $(0.63 \mu \mathrm{M})$ in the absence or presence of TM $(20 \mu \mathrm{M})$ or DFO $(20 \mu \mathrm{M})$ for 24 hours, and then ubiquitinated proteins (Ub) and PARP proteins were analyzed with western blot. GAPDH was used as a loading control. C, control.

caspase 3/8/9 activation (Fig. 6C). Pan-caspase inhibitor z-VAD-fmk could completely inhibit AgDT-induced cleavage of PARP and caspase 3, but it did not attenuate accumulation of ubiquitinated proteins (Fig. 6D). If proteasome inhibition is responsible for apoptosis, it is expected that accumulation of ubiquitinated proteins (proteasome inhibition) would occur before the apoptotic events. As we expected, the results showed that cell apoptosis (PARP 


\section{Cellular Physiology Cell Physiol Biochem 2018;49:780-797 \begin{tabular}{l|l|l} 
DOI: 10.1159/000493041 & $\begin{array}{l}\text { O } 2018 \text { The Author(s). Published by S. Karger AG, Basel } \\
\text { wwww.karger.com/cpb }\end{array}$
\end{tabular} \\ Chen et al.: Inhibition of Proteasomal DUBs by Silver Complex}

cleavage) was observed after proteasome inhibition induced by AgDT (Fig. 6E). Moreover, thiol containing agent TM, but not non-thiol containing agent DFO (ligand L4 in Fig. 3A), completely blocked AgDT-induced proteasome inhibition and apoptosis in NSCLC cells (Fig. $6 \mathrm{~F}$ ). Collectively, these results indicate that AgDT-triggered caspase-dependent apoptosis is a consequential event of the inhibition of cysteine DUBs USP14 and UCHL5.

We also determined the importance of ROS in AgDT-induced proteasome inhibition and cytotoxicity in NSCLC cells. As shown in Fig. 7A, AgDT indeed induced ROS generation, which was completely reversed by both thiol-containing antioxidant (NAC) and enzymatic antioxidant (catalase). Thiol containing antioxidant NAC completely blocked AgDT-induced proteasome inhibition and cell apoptosis; however, catalase only partially reversed AgDTinduced apoptosis, but it did not attenuate AgDT-induced proteasome inhibition (Fig. 7B, C). These results suggest that AgDT-induced apoptosis is only partially dependent on ROS generation.

\section{AgDT inhibits lung tumor growth in vivo}

We further evaluated the antitumor activity of AgDT using A549 and H1299 lung cancer xenograft nude mouse models. In both xenograft models, tumor growth were significantly restrained in the AgDT treatment group (Fig. 8A, D); tumor weights were significantly smaller in the AgDT-treated group compared to the control (Fig. 8B, E), and mouse body weight gradually increased in the control group while kept relatively stable in AgDT treatment group (Fig. 8C, F). The immunohistochemistry staining revealed that the ubiquitinated proteins were obviously increased in the AgDT-treated tumors (Fig. 8G). Together, the results show that AgDT inhibits proteasome function and lung tumor growth in vivo.

We also performed analysis of clinical relevance of USP14 and UCHL5 in NSCLC with publically available database TCGA using UALCAN [30]. The two predominant NSCLC histological phenotypes were adenocarcinoma and squamous cell carcinoma. USP14 and UCHL5 expression was upregulated in lung adenocarcinoma tissues (Fig. 8H), and higher USP14 and UCHL5 expression was associated with poorer survival of lung adenocarcinoma patients (Fig. 8I). However, although USP14 and UCHL5 expression was upregulated in lung squamous cell carcinoma tissues, this upregulation was not associated with a difference in the survival of lung squamous cell carcinoma patients (data not shown). These analyses indicate that pharmacological inhibition of proteasomal DUBs (USP14 and UCHL5) could be an effective approach to searching for NSCLC therapeutics, especially for the adenocarcinoma type.

\section{Discussion}

Copper ions or copper-containing agents have been largely investigated for their ability to inhibit UPS function in cancer cells [8-10]. Copper complex CuPT can induces cancer cell death through targeting both 19S proteasomal DUBs and 20S proteasome peptidases [10], which is distinct from the clinical used proteasome inhibitor bortezomib. In this study, we found that $\mathrm{Cu}$ ions and $\mathrm{Ag}$ ions had basically identical effect on $20 \mathrm{~S}$ proteasomes (Fig. $1 \mathrm{~B}, \mathrm{C})$. Interestingly, compared to $\mathrm{Cu}$ ions, $\mathrm{Ag}$ ions had much stronger inhibitory effect on 19S proteasomal DUBs in vitro (Fig. 1D, E). However, Ca ions had effects on neither 20 proteasome nor proteasomal DUB activities. Since Ag ions bind more strongly to thiols than $\mathrm{Cu}$ ions [31], it can be speculated that $\mathrm{Ag}$ ions may have better ability to interact with cysteine DUBs USP14 and UCHL5. Consistently, $20 \mu \mathrm{M} \mathrm{Ag}$ ions rather than $20 \mu \mathrm{M} \mathrm{Cu}$ or Ca ions induced marked accumulation of ubiquitinated proteins in A549 cells (Fig. 1A). Other reports have revealed that $750 \mu \mathrm{M} C u$ ions induced cell death and increased the amount of polyubiquitinated proteins in human cancer cells [32]. Thus, the fact that a higher dose of $\mathrm{Cu}$ ions is needed to inhibit UPS than Ag ions in live cells may be partially explained by their difference in proteasomal DUB inhibition. It is well known that metal availability in eukaryotes is strictly controlled by intracellular and extracellular high-affinity metal- 


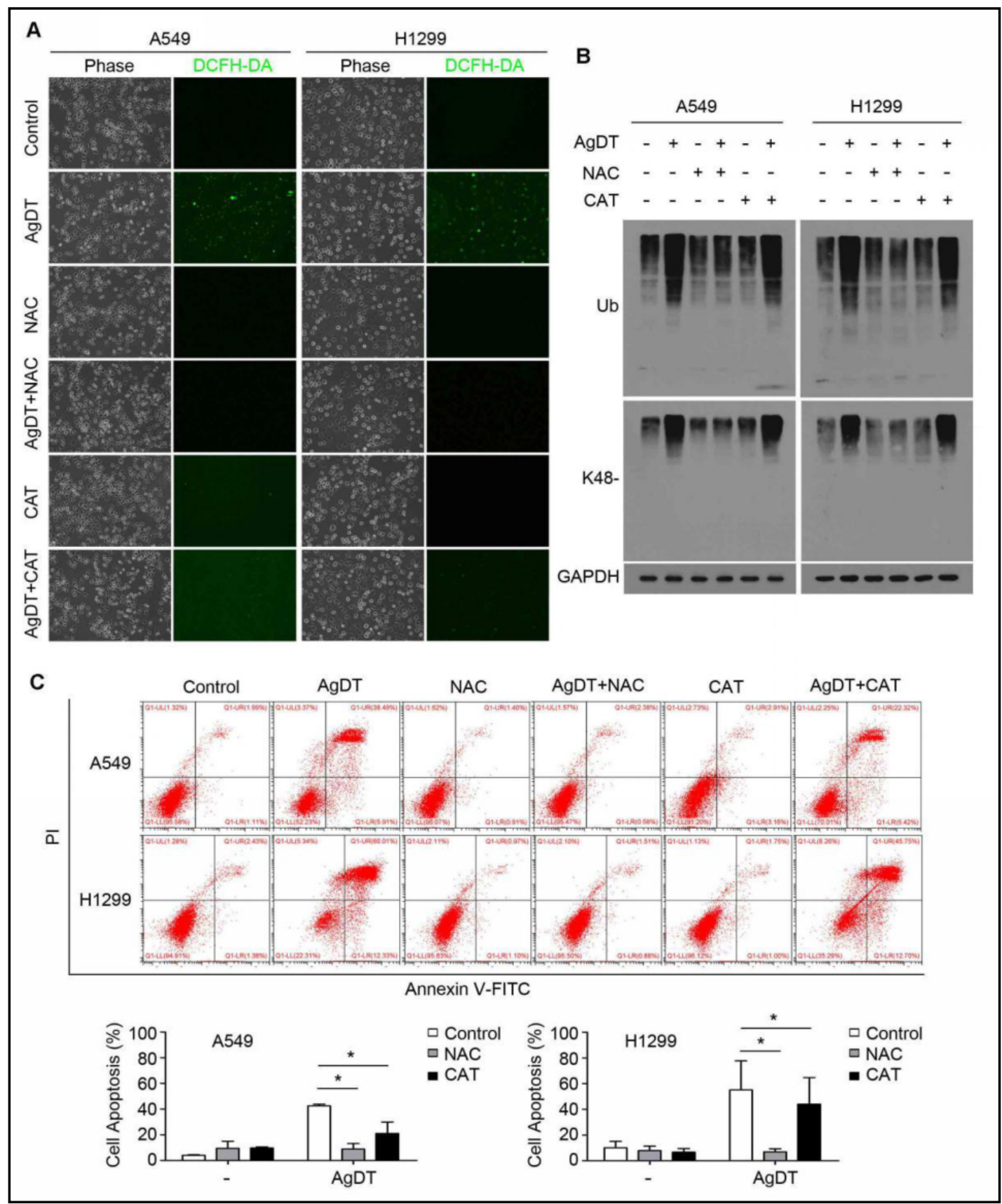

Fig. 7. AgDT-induced apoptosis is partially dependent on ROS production. A, AgDT induces ROS in lung cancer cells. A549 and H1299 cells were pretreated with NAC (5 mM) or catalase (CAT, $2000 \mathrm{U} / \mathrm{ml})$ for 3 hours, followed by $0.63 \mu \mathrm{M}$ AgDT for 3 hours. ROS generation was analyzed using fluorescence microscopy. B, Effects of antioxidant on AgDT-induced accumulation of ubiquitinated proteins. A549 and H1299 cells were pretreated with NAC $(5 \mathrm{mM})$ or catalase (CAT, $2000 \mathrm{U} / \mathrm{ml})$ for 3 hours, followed by $0.63 \mu \mathrm{M}$ AgDT for 6 hours. Total (Ub) and K48-linked (K48-) ubiquitinated proteins were detected by western blot. GAPDH was used as a loading control. C, Effect of antioxidant on AgDT-induced apoptosis. A549 and H1299 cells were pretreated with NAC $(5 \mathrm{mM})$ or catalase (CAT, $2000 \mathrm{U} / \mathrm{ml})$ for 3 hours, followed by $0.63 \mu \mathrm{M}$ AgDT for 24 hours, and the cell apoptosis was determined with Annexin V/PI staining followed by flow cytometry (top). The extent of cell apoptosis was summarized in the associated bar graph (bottom). Mean \pm SD ( $n=3$ ). ${ }^{*} \mathrm{P}<0.05$. 


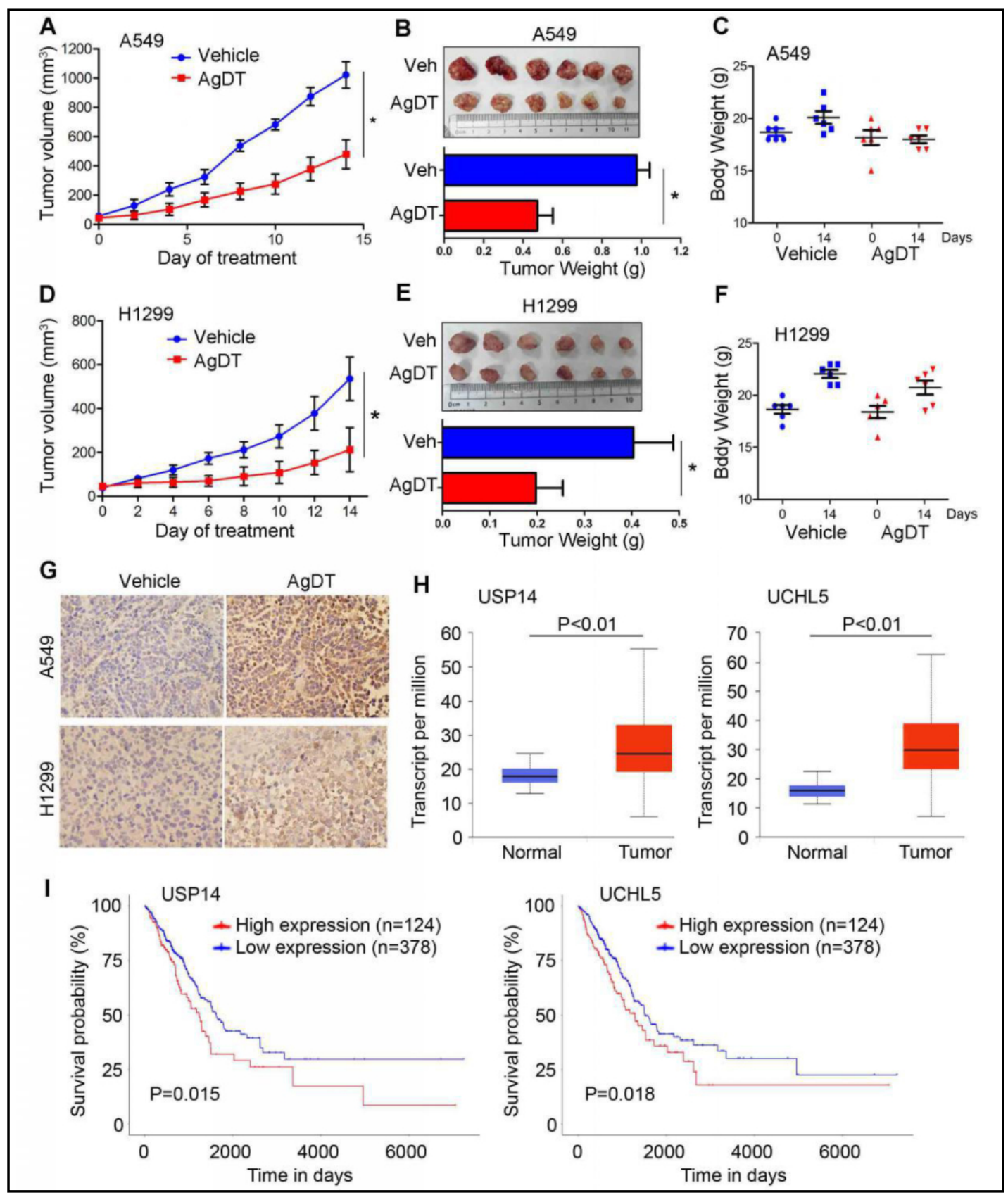

Fig. 8. AgDT inhibits tumor growth in vivo. Nude mice bearing A549 and H1299 lung cancer xenografts were treated with either vehicle control or AgDT $(2.5 \mathrm{mg} / \mathrm{kg} /$ day, intraperitoneally) for 2 consecutive weeks. Tumor growth curves were recorded every other day. Tumor size (A and D), tumor images and tumor weight (B and E), and body weight $(C$ and $F)$ are shown. Mean $\pm S D(n=6) .{ }^{*} P<0.05$ versus control. Veh: Vehicle. G, Representative micrographs of immunohisto- chemistry staining for ubiquitinated proteins (Ub) in nude mouse tumor tissues. H and I, Expression of USP14 and UCHL5 is associated with malignancy in NSCLC patients. H, Expression of USP14 and UCHL5 in normal $(n=59)$ and lung adenocarcinoma $(n=515)$ tissues. I, Association between USP14 and UCHL5 expression and lung adenocarcinoma patient survival.

binding proteins, such as coeruloplasmin and metallothionein. We assume that appropriate lipophilic ligands (such as DSF) could deliver Ag ions into the cell and facilitate the delivery of silver to the proteasome. We found that Ag ions exhibited very strong synergistic cytotoxicity effects with DSF, and Ag/DSF induced UPS inhibition more effectively than Ag ions or DSF

\section{KARGER}




\section{Cellular Physiology Cell Physiol Biochem 2018;49:780-797

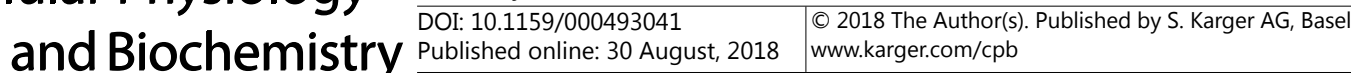 \\ Chen et al.: Inhibition of Proteasomal DUBs by Silver Complex}

alone. Mechanistically, Ag/DSF potently decreased 19S proteasomal DUB activity rather than $20 \mathrm{~S}$ proteasome activity. It was also interesting to note that DSF moderately inhibited $19 \mathrm{~S}$ proteasomal DUB activity in vitro (Fig. $3 \mathrm{H}$ ). This is in line with the findings that DSF or DSF$\mathrm{Cu}$ complexes were identified as $26 \mathrm{~S}$ proteasome inhibitors in a cell-based screening assay $[8,33]$. It is noteworthy that DSF contains thiol-reactive functional groups [16], which can conceivably attack the reactive cysteine in the active site of proteasomal DUBs. Consequently, we synthesized a silver complex AgDT using silver nitrate and DDTC, the active metabolite of DSF. We found that AgDT induced striking accumulation of ubiquitinated proteins in NSCLC cells, without inhibition of the 20 S proteasome (Fig. 5A, B). However, AgDT markedly inhibited the proteasomal DUBs activities, while yielded weak effects on the total cellular DUBs activities (Fig. 5C, D). Moreover, AgDT could block the binding of HA-UbVS to USP14 and UCHL5 in both purified 26S proteasome and NSCLC cells (Fig. 5E, F). These results demonstrate that the metal-based compound AgDT is a novel proteasomal DUB inhibitor. Whether other silver complexes can inhibit proteasomal DUB or 20S proteasomes remains to be further studied. Furthermore, it was previously reported that DDTC-copper complex (CuDT) targeted the NPL4-dependent segregase involved in the processing of ubiquitylated proteins, but not the 20S proteasome and proteasomal metalloprotease DUB (POH1) [19]. Indeed, our results support that the inhibition of USP14 and UCHL5 contributes to the major induction of cell death by AgDT but we cannot exclude the possibility that AgDT also inhibits other potential targets, such as NPL4-dependent segregase.

The discovery of cisplatin in 1965 was a milestone in metal-based cancer chemotherapeutics. Despite platinum agents have great achievements in the treatment of several types of solid tumors including NSCLC, their clinical use suffers from severe side effects and drug resistance [34, 35]. These unresolved drawbacks stimulate the search for novel non-platinum metal-containing anti-tumor agents [36]. In this report, we found that silver complex AgDT showed much stronger cytotoxicity against A549 and H1299 NSCLC cells than against human bronchial epithelial 16HBE cells (Fig. 4D). In addition, we also observed that AgDT induced a marked inhibitory effect on the cell proliferation of PBMC from AML patients while such inhibition was much less on the cells from healthy volunteers (Fig. 4E). In mouse xenograft models, AgDT caused a marked reduction in tumor size with relatively low toxic effect on body weight (Fig. 8A-G). These results suggest that AgDT may selectively inhibit cancer growth both in vitro and in vivo. According to TCGA data, we discovered that USP14 and UCHL5 expression was significantly upregulated in NSCLC tissues compared with the normal tissues. Interestingly, while higher USP14 and UCHL5 expression was associated with poorer survival of lung adenocarcinoma patients, it was not associated with that of squamous cell carcinoma patients. The exact mechanism underlying this discrepancy remains to be defined. Consistently, it was previously reported that USP14 was a tumor-promoting factor, and over-expression of USP14 was associated with poor prognosis in lung adenocarcinoma patients [6]. These results demonstrate that proteasomal DUBs (USP14 and UCHL5) could be promising targets for NSCLC therapeutics, especially for adenocarcinoma and silver complex AgDT is a potential drug candidate.

DUBs of the USP and UCH subfamilies feature a reactive cysteine residue that is prone to oxidation by ROS $[37,38]$. If ROS accumulation is the cause of DUB inhibition in our study, then ROS elimination by antioxidants should prevent the accumulation of ubiquitinated proteins. We observed that scavenging of ROS by catalase, a frequently used ROS-scavenging enzyme [39, 40], could partially prevent AgDT-induced cell apoptosis (Fig. 7A, B); however, it did not affect AgDT-induced accumulation of ubiquitinated proteins (Fig. 7C). These results demonstrate that AgDT-triggered DUB inhibition is not dependent on ROS production. It has been believed that generation of cellular ROS is associated with proteasome inhibitorinduced cell death $[41,42]$. Proteasome inhibition leads to accumulation of misfolded proteins in the endoplasmic reticulum (ER) and thereby induces ER stress, which may cause the accumulation of ROS $[43,44]$. Thus, ROS generation is probably a consequential event of AgDT-induced DUB inhibition. In fact, we found that accumulation of ubiquitinated proteins (DUB inhibition) preceded PARP cleavage (cell apoptosis) induced by AgDT (Fig. 


\section{Cellular Physiology

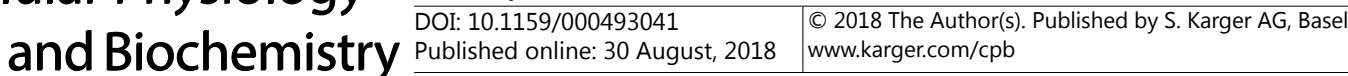 \\ Chen et al.: Inhibition of Proteasomal DUBs by Silver Complex}

6E). Moreover, pan-caspase inhibitor z-VAD-fmk could block AgDT-induced cleavage of PARP and caspase 3, but it did not attenuate AgDT-induced DUB inhibition (Fig. 6D). These results suggest that the inhibition of proteasomal DUBs contributes to AgDT-induced cell apoptosis. Collectively, we conclude that the ROS-generation and proapoptotic potential of AgDT are probably associated with inhibition of proteasomal DUBs.

It has been described that the antitumor activities of silver complexes can be closely related to their interaction with thiol groups of proteins [15]. Thus, we hypothesize that silver complex AgDT can theoretically target the proteasomal DUBs USP14 and UCHL5, which belong to the cysteine protease UCH and USP families. To test this hypothesis, we determined the effects of several thiol-containing agents on Ag ions, Ag/DSF or AgDT induction of cell death and DUB inhibition. We found that thiol-containing metal ligand TM, but not nonthiol-containing metal ligand EDTA completely prevented $\mathrm{Ag}$ ions or $\mathrm{Ag} / \mathrm{DSF}$ from inducing accumulation of ubiquitinated proteins and cell apoptosis (Fig. 3D, E). Consistently, the thiolcontaining agents TM and NAC, but not another non-thiol-containing agent DFO, completely reversed AgDT-induced proteasome inhibition and cell apoptosis (Fig. 6F and Fig. 7B, C). Thus, we submit that thiol-containing agents could directly bind with AgDT or chelate the Ag ions from AgDT, and consequently block the binding of AgDT to cysteine DUBs. These results further confirm that proteasomal DUB inhibition is responsible for AgDT induction of apoptosis.

\section{Conclusion}

In summary, silver complex AgDT inhibits the activities of proteasomal DUBs USP14 and UCHL5, without affecting the 20S proteasome peptidases. Additionally, AgDT triggers accumulation of ubiquitinated proteins and induced apoptosis in NSCLC cells. More importantly, AgDT dramatically suppresses the growth of NSCLC xenografts without obvious side effects. Our findings suggest that targeting of USP14 and UCHL5 may represent a promising therapeutic strategy for NSCLC.

\section{Acknowledgements}

This work was supported by the National High Technology Research and Development Program of China (2006AA02Z4B5), NSFC (81773213/H1609, 81472762/H1609), MOE (20134423110002), Central Financial Grant of China (B16056001), the Science and Technology Program of Guangzhou (201604020001), GD-NSF (2018B030312001), Foundation from Guangdong Provincial Department of Education (2017KCXTD027) (to J. Liu), by Foundation for Young Innovative Talents of Guangdong Province (2016KQNCX136) and GD-NSF (2017A030310151) (to X. Chen), NSFC (81772492/H1615) (to Q. Dou), and by US NIH R01 grants HL072166, HL085629, and HL131667 (to X. Wang).

\section{Disclosure Statement}

The authors declare no conflicts of interest.

\section{References}

1 Adams J: The proteasome: structure, function, and role in the cell. Cancer Treat Rev 2003;29:3-9.

7 Goldberg AL: Protein degradation and protection against misfolded or damaged proteins. Nature 2003;426:895-899.

3 Adams J: The proteasome: a suitable antineoplastic target. Nat Rev Cancer 2004;4:349-360. 


\section{Cellular Physiology Cell Physiol Biochem 2018;49:780-797

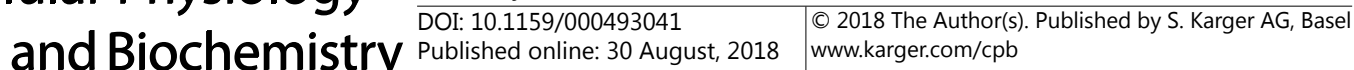

4 Mattern MR, Wu J, Nicholson B: Ubiquitin-based anticancer therapy: carpet bombing with proteasome inhibitors vs surgical strikes with E1, E2, E3, or DUB inhibitors. Biochim Biophys Acta 2012;1823:20142021.

5 D’Arcy P, Brnjic S, Olofsson MH, Fryknas M, Lindsten K, De Cesare M, Perego P, Sadeghi B, Hassan M, Larsson R, Linder S: Inhibition of proteasome deubiquitinating activity as a new cancer therapy. Nat Med 2011;17:1636-1640.

6 Wu N, Liu C, Bai C, Han YP, Cho WC, Li Q: Over-expression of deubiquitinating enzyme USP14 in lung adenocarcinoma promotes proliferation through the accumulation of beta-catenin. Int J Mol Sci 2013;14:10749-10760.

7 Chen Z, Niu X, Li Z, Yu Y, Ye X, Lu S, Chen Z: Effect of ubiquitin carboxy-terminal hydrolase 37 on apoptotic in A549 cells. Cell Biochem Funct 2011;29:142-148.

$>8$ Chen D, Cui QC, Yang H, Dou QP: Disulfiram, a clinically used anti-alcoholism drug and copper-binding agent, induces apoptotic cell death in breast cancer cultures and xenografts via inhibition of the proteasome activity. Cancer Res 2006;66:10425-10433.

-9 Chen D, Cui QC, Yang H, Barrea RA, Sarkar FH, Sheng S, Yan B, Reddy GP, Dou QP: Clioquinol, a therapeutic agent for Alzheimer's disease, has proteasome-inhibitory, androgen receptor-suppressing, apoptosis-inducing, and antitumor activities in human prostate cancer cells and xenografts. Cancer Res 2007;67:1636-1644.

10 Liu N, Liu C, Li X, Liao S, Song W, Yang C, Zhao C, Huang H, Guan L, Zhang P, Liu S, Hua X, Chen X, Zhou P, Lan X, Yi S, Wang S, Wang X, Dou QP, Liu J: A novel proteasome inhibitor suppresses tumor growth via targeting both 19S proteasome deubiquitinases and 20S proteolytic peptidases. Sci Rep 2014;4:5240.

11 Almond KM, Trombetta LD: Copper pyrithione, a booster biocide, induces abnormal muscle and notochord architecture in zebrafish embryogenesis. Ecotoxicology 2017;26:855-867.

$\$ 12$ Klasen HJ: Historical review of the use of silver in the treatment of burns. I. Early uses. Burns 2000;26:117130.

13 Russell AD, Hugo WB: Antimicrobial activity and action of silver. Prog Med Chem 1994;31:351-370.

14 Liau SY, Read DC, Pugh WJ, Furr JR, Russell AD: Interaction of silver nitrate with readily identifiable groups: relationship to the antibacterial action of silver ions. Lett Appl Microbiol 1997;25:279-283.

15 Banti CN, Hadjikakou SK: Anti-proliferative and anti-tumor activity of silver(I) compounds. Metallomics 2013;5:569-596.

16 Johansson B: A review of the pharmacokinetics and pharmacodynamics of disulfiram and its metabolites. Acta Psychiatr Scand Suppl 1992;369:15-26.

17 Iljin K, Ketola K, Vainio P, Halonen P, Kohonen P, Fey V, Grafstrom RC, Perala M, Kallioniemi O: Highthroughput cell-based screening of 4910 known drugs and drug-like small molecules identifies disulfiram as an inhibitor of prostate cancer cell growth. Clin Cancer Res 2009;15:6070-6078.

18 Zhang H, Chen D, Ringler J, Chen W, Cui QC, Ethier SP, Dou QP, Wu G: Disulfiram treatment facilitates phosphoinositide 3-kinase inhibition in human breast cancer cells in vitro and in vivo. Cancer Res 2010;70:3996-4004.

-19 Skrott Z, Mistrik M, Andersen KK, Friis S, Majera D, Gursky J, Ozdian T, Bartkova J, Turi Z, Moudry P, Kraus M, Michalova M, Vaclavkova J, Dzubak P, Vrobel I, Pouckova P, Sedlacek J, Miklovicova A, Kutt A, Li J, et al.: Alcohol-abuse drug disulfiram targets cancer via p97 segregase adaptor NPL4. Nature 2017;552:194-199.

20 Nechushtan H, Hamamreh Y, Nidal S, Gotfried M, Baron A, Shalev YI, Nisman B, Peretz T, Peylan-Ramu N: A phase IIb trial assessing the addition of disulfiram to chemotherapy for the treatment of metastatic nonsmall cell lung cancer. Oncologist 2015;20:366-367.

21 Shi X, Chen X, Li X, Lan X, Zhao C, Liu S, Huang H, Liu N, Liao S, Song W, Zhou P, Wang S, Xu L, Wang X, Dou QP, Liu J: Gambogic acid induces apoptosis in imatinib-resistant chronic myeloid leukemia cells via inducing proteasome inhibition and caspase-dependent Bcr-Abl downregulation. Clin Cancer Res 2014;20:151-163.

22 Li X, Liu S, Huang H, Liu N, Zhao C, Liao S, Yang C, Liu Y, Zhao C, Li S, Lu X, Liu C, Guan L, Zhao K, Shi X, Song W, Zhou P, Dong X, Guo H, Wen G et al.: Gambogic acid is a tissue-specific proteasome inhibitor in vitro and in vivo. Cell Rep 2013;3:211-222.

23 Zhao C, Chen X, Zang D, Lan X, Liao S, Yang C, Zhang P, Wu J, Li X, Liu N, Liao Y, Huang H, Shi X, Jiang L, Liu $\mathrm{X}$, He Z, Wang X, Liu J: Platinum-containing compound platinum pyrithione is stronger and safer than cisplatin in cancer therapy. Biochem Pharmacol 2016;116:22-38. 


\section{Cellular Physiology Cell Physiol Biochem 2018;49:780-797 \begin{tabular}{l|l|l|}
\hline DOI: 10.1159/000493041 & $\begin{array}{l}\text { C) } 2018 \text { The Author(s). Published by S. Karger AG, Basel } \\
\text { www.karger.com/cpb }\end{array}$ \\
\hline
\end{tabular}

24 Medvetz DA, Hindi KM, Panzner MJ, Ditto AJ, Yun YH, Youngs WJ: Anticancer Activity of Ag(I) N-Heterocyclic Carbene Complexes Derived from 4, 5-Dichloro-1H-Imidazole. Met Based Drugs 2008;2008:384010.

-25 Kaplan A, Akalin Ciftci G, Kutlu HM: Cytotoxic, anti-proliferative and apoptotic effects of silver nitrate against H-ras transformed 5RP7. Cytotechnology 2016;68:1727-1735.

-26 Kisselev AF, Callard A, Goldberg AL: Importance of the different proteolytic sites of the proteasome and the efficacy of inhibitors varies with the protein substrate. J Biol Chem 2006;281:8582-8590.

27 Calabro DC, Harrison BA, Palmer GT, Moguel MK, Rebbert RL, Burmeister JL: Thiocyanation, selenocyanation, and halogenation reactions of dithiocarbamate complexes of gold (I) and silver (I). Generation of gold (II) and silver (II) complexes. Inorg Chem 1981;20:4311-4316.

28 Bence NF, Sampat RM, Kopito RR: Impairment of the ubiquitin-proteasome system by protein aggregation. Science 2001;292:1552-1555.

29 Huang H, Zhang X, Li S, Liu N, Lian W, McDowell E, Zhou P, Zhao C, Guo H, Zhang C, Yang C, Wen G, Dong X, Lu L, Ma N, Dong W, Dou QP, Wang X, Liu J: Physiological levels of ATP negatively regulate proteasome function. Cell Res 2010;20:1372-1385.

-30 Chandrashekar DS, Bashel B, Balasubramanya SAH, Creighton CJ, Ponce-Rodriguez I, Chakravarthi B, Varambally S: UALCAN: A Portal for Facilitating Tumor Subgroup Gene Expression and Survival Analyses. Neoplasia 2017;19:649-658.

31 Nies DH: Bacterial Transition Metal Homeostasis; in Nies DH, Silver S (eds). Molecular Microbiology of Heavy Metals. Springer, Berlin, Heidelberg, 2007, vol 6, pp 117-142.

-32 Tardito S, Bassanetti I, Bignardi C, Elviri L, Tegoni M, Mucchino C, Bussolati O, Franchi-Gazzola R, Marchio L: Copper binding agents acting as copper ionophores lead to caspase inhibition and paraptotic cell death in human cancer cells. J Am Chem Soc 2011;133:6235-6242.

33 Lovborg H, Oberg F, Rickardson L, Gullbo J, Nygren P, Larsson R: Inhibition of proteasome activity, nuclear factor-KappaB translocation and cell survival by the antialcoholism drug disulfiram. Int J Cancer 2006;118:1577-1580.

-34 Fennell DA, Summers Y, Cadranel J, Benepal T, Christoph DC, Lal R, Das M, Maxwell F, Visseren-Grul C, Ferry D: Cisplatin in the modern era: The backbone of first-line chemotherapy for non-small cell lung cancer. Cancer Treat Rev 2016;44:42-50.

35 Florea AM, Busselberg D: Cisplatin as an anti-tumor drug: cellular mechanisms of activity, drug resistance and induced side effects. Cancers (Basel) 2011;3:1351-1371.

36 Ott I, Gust R: Non platinum metal complexes as anti-cancer drugs. Arch Pharm (Weinheim) 2007;340:117126.

37 Cotto-Rios XM, Bekes M, Chapman J, Ueberheide B, Huang TT: Deubiquitinases as a signaling target of oxidative stress. Cell Rep 2012;2:1475-1484.

-38 Lee JG, Baek K, Soetandyo N, Ye Y: Reversible inactivation of deubiquitinases by reactive oxygen species in vitro and in cells. Nat Commun 2013;4:1568.

-39 Raj L, Ide T, Gurkar AU, Foley M, Schenone M, Li X, Tolliday NJ, Golub TR, Carr SA, Shamji AF, Stern AM, Mandinova A, Schreiber SL, Lee SW: Selective killing of cancer cells by a small molecule targeting the stress response to ROS. Nature 2011;475:231-234.

-40 Trachootham D, Zhou Y, Zhang H, Demizu Y, Chen Z, Pelicano H, Chiao PJ, Achanta G, Arlinghaus RB, Liu J, Huang P: Selective killing of oncogenically transformed cells through a ROS-mediated mechanism by betaphenylethyl isothiocyanate. Cancer Cell 2006;10:241-252.

41 Ling YH, Liebes L, Zou Y, Perez-Soler R: Reactive oxygen species generation and mitochondrial dysfunction in the apoptotic response to Bortezomib, a novel proteasome inhibitor, in human H460 non-small cell lung cancer cells. J Biol Chem 2003;278:33714-33723.

42 Brnjic S, Mazurkiewicz M, Fryknas M, Sun C, Zhang X, Larsson R, D’Arcy P, Linder S: Induction of tumor cell apoptosis by a proteasome deubiquitinase inhibitor is associated with oxidative stress. Antioxid Redox Signal 2014;21:2271-2285.

43 Bush KT, Goldberg AL, Nigam SK: Proteasome inhibition leads to a heat-shock response, induction of endoplasmic reticulum chaperones, and thermotolerance. J Biol Chem 1997;272:9086-9092.

$\checkmark 44$ Haynes CM, Titus EA, Cooper AA: Degradation of misfolded proteins prevents ER-derived oxidative stress and cell death. Mol Cell 2004;15:767-776. 